Griffin, J. M., Fuhrer, R., Stansfeld, S. A., Marmot, M., 2003. "The importance of low control at work and home on depression and anxiety: Do these effects vary by gender and social class", Social and Economic Patterning of Health among Women / Les facteurs sociaux et économiques de la santé des femmes, Arber S. and Khlat M., (eds.), Paris, CICRED, 2003, pp. 297-330.

\title{
THE IMPORTANCE OF LOW CONTROL AT WORK AND HOME ON DEPRESSION AND ANXIETY: DO THESE EFFECTS VARY BY GENDER AND SOCIAL CLASS?*
}

\author{
Joan M. GRIFFIN ${ }^{1}$, Rebecca FUHRER ${ }^{1}$, \\ Stephen A. STANSFELD ${ }^{2}$, and Michael MARMOT ${ }^{1}$ \\ ${ }^{1}$ Department of Epidemiology and Public Health, \\ University College London, London, UK \\ 2 Basic Medical Sciences Building, \\ Queen Mary and Westfield College, London, UK
}

\begin{abstract}
In this study we consider both a gender model, a model that focuses on the stress associated with social roles and conditions in the home environment, and a job model, which addresses the stressful characteristics of the work environment, to investigate patterns of women's and men's psychological morbidity across different social positions. Using data from the Whitehall II Study, a longitudinal study of British civil servants, we hypothesise that a lack of control in the home and work environments affects depression and anxiety differently for women and men and across three social class groups. Both women and men with low control either at work or at home
\end{abstract}

* This paper has already been published in Social Science and Medicine, special issue, vol. 54, no. 5, March 2002, p. 783-798. 
had an increased risk of developing depression and anxiety. We did not find an interaction between low control at home and work. We did, however, find that the risks associated with low control either at home or work were not evenly distributed across different social positions, measured by employment grade. Women in the lowest or middle employment grades who also reported low control at work or home were at most risk for depression and anxiety. Men in the middle grade with low work. control were at risk for depression while those in the lowest grade were at risk for anxiety. Men in the middle and highest grades, however, were at greatest risk for both outcomes if they reported low control at home. We conclude that, in addition to social roles and characteristics of the work environment, future investigations of gender inequalities in health incorporate variables associated with control at home and social position.

Keywords: Depression, Anxiety, Health inequalities, Gender inequalities, Control, Work, Home.

\section{Résumé}

Dans cette étude, les auteurs examinent à la fois un "modèle du genre ", axé sur le stress associé aux rôles sociaux et aux maladies dans l'environnement domestique, et un "modèle de l'emploi », qui porte sur les caractéristiques stressantes de l'environnement professionnel, afin d'analyser la morbidité psychologique respective des hommes et des femmes dans diverses situations sociales. Exploitant les données de l'enquête "Whitehall II », une étude longitudinale sur les fonctionnaires britanniques, ils font l'bypothèse qu'un manque de maîtrise sur l'environnement domestique et professionnel influe sur la dépression et l'angoisse de manière différente selon le sexe et la classe sociale. Les personnes des deux sexes qui manquent d'autonomie, soit au travail soit à la maison, ont un risque accru de dépression et d'angoisse. Les auteurs n'ont pas constaté d'effet d'interaction entre le manque d'autonomie à la maison et le manque d'autonomie au travail. Mais ils ont observé que les risques associés au manque de maitrise sur son environnement, domestique ou professionnel, ne sont pas équitablement répartis entre les classes sociales (représentées par la position hiérarchique au travail). Les femmes des échelons professionnels inférieurs ou intermédiaires qui se plaignent de manquer d'autonomie, au travail ou à la maison, sont les plus exposées au risque de dépression et d'angoisse. Les hommes des échelons professionnels intermédiaires qui ont peu d'autonomie au travail sont sujets à la dépression, alors que ceux des échelons inférieurs sont plutôt sujets à l'anxiété. Cependant, les hommes qui occupent une position professionnelle médiane ou supérieure sont davantage exposés à ces deux risques s'ils se plaignent de manquer d'autonomie à la maison. Les auteurs concluent qu'en plus des rôles sociaux et des caractéristi- 
ques de l'environnement professionnel, les futures recherches sur les inégalités de genre en matière de santé doivent prendre en compte des variables associées à la maitrise sur l'environnement domestique et à la position sociale.

Mots-clés: Dépression, Angoisse, Inégalités en matière de santé, Inégalités de genre, Maîtrise, Travail, Foyer.

\section{Introduction}

Numerous studies have shown that women experience higher rates of depression and anxiety than men (Aneshensel, 1992; Gove and Tudor, 1973; Kessler and McRae, 1981; Mirowsky and Ross, 1989). In spite of this evidence, researchers still do not fully understand the source of these differences. In this paper we use data from the Whitehall II Study, a longitudinal study of British civil servants, to investigate two possible factors that, separately or together, may lead to psychological strain and contribute to these different patterns of depression and anxiety: low control at work, and low control at home. Furthermore, we examine if control at work and home varies by social position in order to determine if certain groups of women or men with low control are at higher risk for depression and anxiety.

For this investigation we draw from two existing theoretical frameworks that examine the relationships among stressful characteristics and poor health outcomes and then create a model that incorporates potential stressors from work and home. We consider both a gender framework, that is, one that focuses on the stress associated with roles and stressful conditions in the home environment, as well as a job framework, which addresses the stressful characteristics in the work environment.

We expected control at home to contribute more to the risk for depression and anxiety in women and control at work to contribute more for men. We also believed that across levels of social position, measured by employment grade, we would find a gradient in risk and that job and home control would explain part of this pattern.

Following a review of the literature relating social position and control to psychological distress and an explanation of the different theories about the relationship among work, home, and health that helped inform and guide this investigation, we present our findings to 
four research questions. First, does low control at work increase the risk of depression and anxiety equally for women and men? Second, does low control at home increase the risk of depression and anxiety equally for women and men? Third, is there an interaction between control at home and control at work that increases the risk for psychological distress? Fourth, do these effects vary by social position, and if so, do women and men in different social positions have a greater risk of depression or anxiety from low control at home or at work?

\section{Background}

Studies in industrialised countries have consistently shown an unequal distribution of mortality for both men and women across different social classes, with people at the lower end of the social hierarchy dying at a faster rate than those at the top (Townsend and Davidson, 1982; McDonough et al., 1999). Although the pattern is less clear, researchers have also found a social class gradient for psychological morbidity (Dohrenwend, 1990). Higher rates of emotional distress, pain, tiredness, and mental illness have been found in those with lower rather than higher social positions (Hunt et al., 1985), but for so-called minor psychiatric disorders (largely depression and anxiety) the evidence for a social gradient is less clear. Some studies have found higher rates among those with lower socio-economic status (Kessler, 1994; Bebbington et al., 1981; Hodiamont et al., 1987) while others (Hare and Shaw, 1965; Lin et al., 1989) have found no social class gradient.

Theorists have suggested that one explanation for the social gradient in rates of minor psychiatric disorders is that people in lower social positions are confronted with a disproportionate number of chronic stressors and negative life events and relatively few material and social resources (Kessler, 1994; Pearlin, 1989). Feminist scholars have advanced this theory, suggesting that, generally, women, with their lower position in society, are particularly at risk for psychologically morbid conditions (Hall et al., 1993). Employed women, however, may have more potential to improve their social position by accumulating more resources, securing more social support, achieving greater prestige, and gaining greater control and power within the family (Rosenfield, 1989), thus, lowering their rates of depression and anxiety. In support of this, studies have shown that during the 1950's to 1970's, as large numbers of women moved into the waged labour market, the difference in 
women's and men's rates of psychological morbidity narrowed (Kessler and McRae, 1981; McLanahan and Glass, 1985). Similarly, when compared to housewives, employed women have lower mortality rates (Passannante and Nathanson, 1985), better perceived health status (Nathanson, 1980; Verbrugge, 1983), and lower rates of depression (Hall and Johnson, 1988). Yet studies that have taken into account the "second shift" (Hochschild, 1989), that is, the double burden of being employed and maintaining primary responsibilities for the family and home, have shown that employed women have similar or even higher rates of psychiatric symptoms than housewives (Haavio, 1986). Women who work full time, especially those in managerial and professional jobs (Bartley et al., 1992; Hall, 1992; Rosenfield, 1989; Walters et al., 1996), and who have dependent children (Arber et al., 1985; Hall, 1992) also report more ill-health and depressive symptoms than their part-time or childless counterparts. These findings suggest that for women who work full time and maintain the overall management of the home environment, there may be a threshold where the benefits of paid employment begin to reverse and become deleterious. It is unclear, however, what causes this reversal, if some women reach this threshold earlier than others, and if the same pattern holds for men who have greater responsibilities at home. Arber $(1991,1997)$ has suggested that in order to unravel this pattern, researchers need to understand the structural context in which women perform their paid and unpaid work and live out their social roles. In other words, to understand the impact of work and social roles on health, we must also take into consideration social position and the level of control over resources that certain positions in society afford women.

With Arber's advice in mind, we argue in this paper that the benefits of employment begin to reverse and become deleterious when women, especially those in lower social positions, find themselves lacking control over their work or home life. In the psychosocial work environment literature, numerous studies (described in more detail below) have shown the harmful health effects of low job control, particularly for men (Warr, 1990) and men in low social positions (Marmot et al., 1991), yet far fewer studies have investigated the possible main or mediating effects low control in the home environment has in relation to health outcomes (Walters et al., 1996; Schooler et al., 1983; Rosenfield, 1989; Lombardi and Ulbrich, 1997). More common, however, are investigations comparing the stressful characteristics of paid work and unpaid work done at home. These two types of work have a 
different historical and social context, but researchers often characterize them in similar terms: isolated, monotonous, and demanding activity, often with low status, that provides little control over the sources of stress (Ferree, 1990; Oakley, 1974; Kessler-Harris, 1976; Bird and Ross, 1993).

In this next section, we describe the different theoretical frameworks from which we draw to develop a model that incorporates elements from both the home and work environments.

\section{Theoretical approaches}

In order to describe the stressful circumstances that are often associated with depression and anxiety, researchers have commonly used a different theoretical framework for women than for men. The framework for women primarily focuses on the strain from social roles within the family where, it is thought, the antecedents for distress may be rooted, and secondarily, on strain from paid employment. For men, however, the framework is apt to examine only stressful characteristics of paid work. A more detailed explanation of these frameworks follows.

\subsection{Gender framework}

Theories about the effects of family, home, and work on psychological distress draw from a number of academic disciplines. In general, they attempt to explain the health effects associated with the struggle to balance home and job responsibilities by incorporating an understanding of women's experiences and opportunities, their position in society, place in the labour market, and roles at home and within the family. From some of the common theories come the following models.

\subsubsection{The spillover model}

The spillover model has been used to help explain how strain may result from the intersecting relationship from two separate work environments, the paid ("work") and unpaid ("home"). It recognises that boundaries exist between work and home, yet it finds those boundaries permeable. Acknowledging that work and home often have stressful 
exposures in common, the model states that these exposures sometimes "spillover", or reciprocate, from one environment to another and eventually can lead to work/family conflict that results in negative health outcomes (Frone et al., 1996; Grzywacz and Marks, 2000; Wortman et al., 1991). Using spillover theory, one could hypothesise that feelings about consistently missing family events because of work, or being overwhelmed with demands from home while at work would cause poor health outcomes, such as depression and anxiety. In a longitudinal study of 267 employed parents who worked more than 20 hours a week, Frone (1997), for example, found that family to work spillover was related to depression and poor physical health while work to family spillover was more closely associated with negative health behaviours, such as heavy alcohol consumption. Interestingly, after controlling for spillover (both work to family and family to work), women and men's reports of depression, poor physical health or heavy alcohol use did not differ significantly.

\subsubsection{The double exposure model}

The double exposure (or double burden) model incorporates the principles of the spillover model, but it also recognises the uniqueness of each environment. Instead of focusing specifically on the crossover or interaction between work and home, the double exposure model suggests that exposure to stress occurs in both the home and work environment, with some exposures unique to each environment, and others common to both. If levels of total exposure (common and unique elements from both environments) are high, the risk for negative health outcomes increases (Hall, 1992; Lundberg et al., 1994). Hall (1992) used this approach to study exposures to stress from work and home and their combined effect on psychosomatic strain and found fundamental gender differences in "...the pattern of exposure to the stresses and the rewards of working and home life" (p. 253), and the relationship of this pattern to strain. In her study of 12,772 working Swedish men and women, the greatest odds for psychosomatic strain was for women who worked more than 20 hours a week, had high home stress (defined as the level of burden from household duties) and low control on the job. Women were almost five times $(\mathrm{OR}=4.85)$ more likely to have psychosomatic strain under these conditions, while for men, these same factors seemed to be protective $(\mathrm{OR}=0.25)$. 


\subsubsection{Learning generalisation theory}

Schooler and colleagues (1983) have developed a model of "housework" that is analogous to their model for paid employment. Briefly, they hypothesise that like waged work, the characteristics of housework, specifically the psychological and physical demands, routinisation, complexity, and level of responsibility, independence, and control associated with domestic work, shape people's psychological functioning. They propose that people engaged in housework that requires intellectual activity, diversity of tasks and authority over their work have better psychological functioning, while those participating in monotonous work, lacking cognitive challenge and control, have poorer psychological functioning. In a test of their model, Schooler et al. (1983) found that distress in women who were not employed was related to the frequency of having to do housework under time pressure or the frequency of being held responsible for things outside her control. Similar to the women not employed, distress among employed women was related to the frequency of situations in which a woman is held responsible for things outside of her control, and for employed men, the time pressure for doing housework. As expected, both employed women and housewives reported better psychological functioning if their household tasks were cognitively challenging and required independent judgement. This was not the case for men, however. Men's positive psychological functioning was associated more with the heaviness of physical labour, perhaps suggesting that men's and women's experiences of household work are defined differently, and therefore, affect psychological functioning differently.

\subsubsection{Multiple role theory}

Moen (1989), in a different approach to that of Schooler et al. (1983), describes three theoretical explanations of how multiple roles (e.g., employee, parent, spouse) may affect health: role enhancement, role strain, and the role context approach. Role enhancement theory posits that additional roles can lead to better health outcomes because resources, support and prestige accompany every new role. On the other hand, the accumulation of roles can lead to role strain because with the increase in roles there comes additional demands and obligations that participation in each role requires - and such strain can be deleterious. Role context theory proposes that, in addition to the num- 
ber of roles, the context and characteristics of each particular role are important factors in determining whether the role accumulation produces beneficial or negative health effects. In other words, role context theory emphasises not only the occupation of a role, but the specific characteristics of each role, the way in which it is performed and the value placed upon it by society and by the person. It acknowledges that the role of a parent, spouse, or caregiver may be significantly different than the role of an employee. Role context theory would hypothesise that psychological strain does not develop simply as a result of being employed and being a parent or spouse, but that the context of these roles (e.g., their conflict and compatibility) and their characteristics (e.g., their rewards, benefits, demands, and detriments) are the factors important to understanding the extent and nature of strain and other health outcomes.

\subsection{Job stress framework}

The dominant model used to conceptualise how stressful characteristics of the job can lead to psychological strain has been the job strain or demand/control model. Developed by Karasek and Theorell (Karasek, 1979; Karasek and Theorell, 1990), and modified by Johnson et al. (1989), this model posits that deleterious strain will occur when high psychological demands on the job (the pace, effort, and volume of work) coexist with low control over the work. Low control is described more specifically in this model as 'decision latitude', yet the terms are often used interchangeably in the job stress literature. For this study we use the term decision latitude when we discuss our investigation. Karasek and Theorell (1990) define decision latitude as a lack of authority to make decisions concerning the work (called decision authority) and the inability to use one's skills at work (called skill discretion). In theory, chronic exposure to job conditions that are high in demands and low in decision latitude can lead to psychological strain, strain that may manifest as depression or anxiety.

This model has been used in numerous studies to examine the relationship among job characteristics, psychological strain, and psychological and physical illnesses (Schnall et al., 1994; Stansfeld et al., 1995; Stansfeld et al., 1999). Many of these studies have used national, population-based databases, thus gaining stronger credibility for extrapolating their results to other populations (Alfredsson and Theorell, 1983; Johnson and Hall, 1988; Theorell et al., 1991). In many of the 
larger studies, decision latitude has been the key construct in the model. Empirical evidence strongly supports the construct of control as the theoretical basis for the model and its importance as a systematic function of social class (Johnson and Hall, 1995). In Schnall et al.'s (1994, p. 400) review of studies investigating the relationship between the job strain model and cardiovascular disease symptoms and events, for instance, 17 of 25 studies showed a significant main effect of job control on the cardiovascular outcomes, while only 8 of 23 studies showed a main effect of job demands and the outcome. In the Whitehall II Study, we have found that low decision authority and skill discretion predict future development of coronary heart disease for both men and women (Bosma et al., 1997). Likewise, both decision authority and skill discretion make powerful contributions to explaining employment grade differences in depression in men, but not women, and employment grade differences in well being for both men and women (Stansfeld et al., 1998).

In our investigation we take into consideration elements of all these models. We examine a parallel construct for each environment, control, measure the occupancy of important roles (employee, parent, spouse, and caregiver), and then attempt to understand the context and social structure in which these roles are performed and their impact on psychological health for women and men.

\section{Methods}

\subsection{Data and sample}

The Whitehall II project is a longitudinal cohort study examining the causes of morbidity and mortality differences across the social gradient. From 1985 to 1988, all civil servants between the ages of 35-55 who worked for one of twenty London-based government civil service 
Griffin, J. M., FuHRER, R., StAnSFEld, S. A., MARmot, M., 2003. "The importance of low control at work and home on depression and anxiety: Do these effects vary by gender and social class", Social and Economic Patterning of Health among Women / Les facteurs sociaux et économiques de la santé des femmes, Arber S. and Khlat M., (eds.), Paris, CICRED, 2003, pp. 297-330.

$$
\text { Table } 1
$$

Demographic variables by gender and employment grade at Phase 3

\begin{tabular}{|c|c|c|c|c|c|c|c|c|}
\hline & \multicolumn{4}{|c|}{ Men } & \multicolumn{4}{|c|}{ Women } \\
\hline & $\begin{array}{c}\text { High } \\
\text { grade } \\
(n=2,466) \\
\%\end{array}$ & $\begin{array}{c}\text { Medium } \\
\text { grade } \\
(n=2,343) \\
\%\end{array}$ & $\begin{array}{c}\text { Low } \\
\text { grade } \\
(n=357) \\
\%\end{array}$ & $p$-value* & $\begin{array}{c}\text { High } \\
\text { grade } \\
(n=376) \\
\%\end{array}$ & $\begin{array}{c}\text { Medium } \\
\text { grade } \\
(n=1,031) \\
\%\end{array}$ & $\begin{array}{c}\text { Low } \\
\text { grade } \\
(n=896) \\
\%\end{array}$ & $p$-value* \\
\hline $\begin{array}{l}\text { Marital status } \\
\text { Married }\end{array}$ & 89.6 & 77.7 & 59.0 & $<0.01$ & 64.9 & 61.2 & 67.2 & 0.13 \\
\hline Age group & & & & & & & & \\
\hline $39-44$ & 25.8 & 34.7 & 29.4 & $<0.01$ & 37.5 & 29.9 & 13.2 & $<0.01$ \\
\hline $45-49$ & 31.6 & 30.9 & 21.3 & & 31.9 & 26.7 & 24.3 & \\
\hline $50-54$ & 22.7 & 17.3 & 21.3 & & 19.4 & 21.9 & 25.3 & \\
\hline 55-64 & 19.9 & 17.1 & 28.0 & & 11.2 & 21.5 & 37.2 & \\
\hline Number of children & & & & & & & & \\
\hline No children & 17.8 & 32.2 & 48.5 & $<0.01$ & 61.2 & 53.2 & 23.6 & $<0.01$ \\
\hline One child & 10.2 & 12.4 & 8.7 & & 12.2 & 16.7 & 13.4 & \\
\hline Two children & 45.5 & 37.2 & 23.1 & & 20.2 & 19.9 & 35.0 & \\
\hline Three or more children & 26.4 & 18.2 & 19.7 & & 6.4 & 10.2 & 28.1 & \\
\hline $\begin{array}{l}\text { Caregiving status } \\
\text { Caregiver }\end{array}$ & 8.9 & 10 & 8.1 & 0.62 & 13.3 & 14.4 & 12.7 & 0.57 \\
\hline
\end{tabular}

* Differences in proportions tested using likelihood-ratio chi-square. 
departments were sent introductory letters and questionnaires that included information on demographics, work characteristics, and physical and mental health. The overall response rate was 73\% $71 \%$ for women and $74 \%$ for men). The true response rates, however, were likely higher because approximately four percent of those on this list of employees had, in fact, moved before the study and, thus, were not eligible for inclusion. In all, 10,308 workers - 6,895 men (67\%) and 3,413 women $(33 \%)$ - agreed to participate. Since the initial baseline phase, this cohort has participated in 4 additional phases of data collection. In Phases 2 (1989-90) and 4 (1995-96), participants completed postal questionnaires; in Phases 3 (1991-93) and 5 (1997-99) they answered questionnaires and underwent additional screening examinations.

Data collected in Phases 3 and 5 were used in this investigation. Unless noted otherwise, we used the demographic, social position, decision latitude, control at home and social roles variables from Phase 3 and depression and anxiety data from Phase 5 . At Phase 3, $81 \%$ of the original cohort (8,318, total; 5,739 men, 2,579 women) completed the postal questionnaire, while in Phase 5, 71\% (7,270, total; 5,091 men, 2,179 women) completed the survey. The length of follow up between Phase 3 and Phase 5 was, on average, 5 years. Participants who had retired from paid work by Phase 3 or did not have complete data were not included in these analyses. Of the remaining 7,473 participants from Phase 3, 69\% $(n=5,170)$ were men and 31\% $(n=2,303)$ were women. Additional demographic characteristics are found in Table 1.

\subsection{Measures}

\subsubsection{Social position}

Social position was determined by employment grade within the civil service. Participants' report of their current grade during Phase 3 was used in these analyses. Explanations on how civil service grades are established are reported elsewhere (Marmot et al., 1991). Approximately 38\% were classified in the administrative (high) grades, $45 \%$ professional/executive (middle) grades, and 17\% worked in the cleri$\mathrm{cal} /$ support (low) grades. Proportionally more men than women worked in higher-grade jobs (48\% versus 16\%), while more women 
worked in lower-grade jobs (39\% versus 7\%). The same proportion of women and men $(45 \%)$ worked in the middle grade.

\subsubsection{Job and home factors}

Statements from the Phase 3 questionnaire were used to measure decision latitude and control at home. For control at home, participants responded to the following statement using one of 6 response categories (disagree strongly, disagree moderately, disagree slightly, agree slightly, agree moderately, agree strongly): At home, I feel I have control over what happens in most situations. Responses were recoded into a dichotomous variable (disagree/agree) and labelled low control ('disagree') and high control ('agree'). Low control was coded as 1, high control as 0 .

Respondents also answered a series of 15 statements regarding decision latitude based on Job Content Questionnaire of Karasek et al. (1985). This scale consists of two sub-scales: decision authority, with 9 items; and, skill discretion, with 6 items. Responses for these questions were 'often', 'sometimes', 'seldom', 'never/almost never' and scored from one to four. Answers were summed and then recoded into a dichotomous variable (high $=0$, low $=1$ ). Because the median was significantly different for women and men, gender-specific cut points were used to create the dichotomous variable.

Data concerning full-time versus part-time employment status were not collected at Phase 3, but were collected at Phase 5. Instead of simply using employment status at Phase 5 as a proxy for Phase 3 status in all of the analyses, however, we first examined how full- and part-time workers differed, then repeated our multivariate analyses to test for the effect of employment status on depression and anxiety and compared those results to our main findings. Approximately $13 \%$ of participants with data at Phase 5 reported they worked less than 30 hours per week. Of those 13\%, 9\% were men and 4\% were women. The proportion of women working part-time was relatively even across the three employment grades, but men working part-time were most likely to be working in the highest level of the civil service. The majority of women and men part-timers were older than 50 years, suggesting that these people were beginning a transition into retirement. Including employment status did not alter our main multivariate findings; therefore, we do not report these data. 
At Phase 3 we asked participants about marital status, if they were providing any personal care or help to an aged or disabled relative, and the number of children they had. We coded marital and caregiving status as dichotomous variables $(1=$ unmarried, $1=$ caregiver $)$ and number of children as a categorical variable $(0=$ no children to $3=3$ or more children).

\subsubsection{Psychological morbidity}

Psychological morbidity was measured at both Phases 3 and 5 using the 30-item General Health Questionnaire (GHQ) (Goldberg, 1972) which has been validated against the Clinical Interview Schedule in a study sub-sample (Stansfeld and Marmot, 1992). The GHQ is a well-established screening questionnaire for minor psychiatric disorder suitable for use in general and clinic population samples.

For this investigation we were interested in the more specific psychopathology of depression and anxiety rather than in general psychiatric disorders, and therefore, we used two sub-scales of the 30-item GHQ. Researchers have repeatedly tested the validity and reliability of depression and anxiety sub-scales from the 28-item GHQ, a shorter GHQ scale with additional questions regarding depression and anxiety (Goldberg and Hillier, 1978). We selected the items from the 30-item questionnaire that were also present in the depression and anxiety subscales of the scaled 28-item GHQ (Stansfeld et al., 1995). We chose four items for depression and five items for anxiety and analysed their internal consistency and principal components structure. The depression and anxiety sub-scales had alpha coefficients of 0.88 and 0.86 , respectively. In principal components analysis of the 30-item GHQ, we found five factors with eigenvalues greater than one after the items were rotated. The four items we chose for the depression sub-scale loaded on a single component for both women and men. All but one of the five items from the anxiety sub-scale also loaded on one factor for women and men.

Depression items were as follows: 'Have you recently: 1) been thinking of yourself as a worthless person; 2) felt that life is entirely hopeless; 3) felt that life isn't worth living; 4) found at times you couldn't do anything because your nerves were too bad?'

Anxiety items were as follows: 'Have you recently: 1) lost much sleep over worry; 2) felt constantly under strain; 3) been getting scared 
or panicky for no good reason; 4) found everything getting on top of you; 5) been feeling nervous and strung up all the time?'

Responses for depression and anxiety items were 'not at all', 'no more than usual', 'rather more than usual', and 'much more than usual'. All items were scored on a Likert scale from 0 to 3 and then summed. We created a dichotomous variable for case status, using the top quartile for cases and the remainder as non-cases.

\subsection{Procedures}

In our bivariate analyses, we examined the distribution of demographic and social role variables, GHQ mean scores, percentage of GHQ cases, depression cases, and anxiety cases, and the percentage of those reporting high and low control by gender and employment grade.

For the multivariate analyses, separate analyses were conducted for women and men. Adjusting for age and employment grade, we used hierarchical logistic regression models to examine the relationship among job control, home control, and caseness for each of the outcomes (depression and anxiety). We used this approach in order to examine the independent effects of decision latitude and control at home on depression and anxiety, but also to determine if employment grade varied when there was low control. Moreover, we were interested in how the addition of social roles to the models might alter these relationships.

We used four steps to build the models. For Step 1, age and employment grade were fit. Decision latitude and home control were added in Steps 2 and 3. To address our first question - does low decision latitude increase the risk of depression and anxiety equally for women and men - we first fit decision latitude in Step 2 and then fit home control to determine if it altered the main effect decision latitude had on the outcomes. To address our second question - does low control at home increase the risk of depression and anxiety equally for women and men - we fit home control in Step 2 and then fit decision latitude in Step 3. Lastly, we included number of children, marital status, and caregiving status in Step 4 to see the effect of additional domestic roles on the outcomes. We then examined an identical set of models, but added an interaction term of decision latitude by home control. In order to remove the potential confounding effect of caseness at Phase 3, results from the hierarchical analyses were confirmed 
both by repeating the analyses adjusting for Phase 3 caseness, as well as by excluding Phase 3 cases. As both approaches gave comparable results, only the latter are reported in the tables. Non-cases at Phase 3 were defined in the same way as at Phase 5: all those with summed GHQ scores not in the top quartile.

Finally, to determine who had the highest risk for depression and anxiety given their level of control on the job and at home, we stratified the sample by grade and gender. We then compared women and men's risk for depression and anxiety from home control and decision latitude by employment grade.

\section{Results}

In the unadjusted bivariate analyses of demographic and social role variables, men were significantly more likely to be married, younger, and have more children than women. As shown in Table 1, nearly $90 \%$ of men in the highest grade were married compared to only $65 \%$ of women in the same employment grade. For men we found a gradient in marital status, with men in the highest grade the most likely to be married (89.6\%) and men in the lowest grade the least likely $(59 \%)$. We did not find the same pattern among women; instead, the proportion of married women across the three employment grades was relatively even. The number of children participants reported having also varied by gender. Women in the highest and middle grades were more likely than men in the same grades not to have any children. Over half of the women in the high and middle grades reported not having any children, compared to $18 \%$ of men in the high and $32 \%$ in the middle grade. Conversely, nearly $50 \%$ of men in the lowest grade did not have children, compared to only $24 \%$ of the women in the same grade. Women were more likely than men to care for older relatives, but neither men nor women in any particular employment grade were more likely to provide this care.

Consistent with findings from previous studies (Aneshensel, 1992; Gove and Tudor, 1973; Kessler and McRae, 1981; Mirowsky and Ross, 1989), women were significantly more likely than men to suffer from psychological ill health. More often than men, women were classified as a 'case' using the 30-item GHQ and depression and anxiety sub- 
Table 2

Psychological morbidity at Phase 5, and control on the job and at home by gender and employment grade at Phase 3

\begin{tabular}{|l|c|c|c|c|}
\hline & High grade & Medium grade & Low grade & $p$-value \\
\hline Men & & & & \\
GHQ mean (sd) & $2.69(4.98)$ & $3.11(5.62)$ & $3.38(6.20)$ & 0.02 \\
$\%$ of GHQ cases $(n)$ & $20.0 \%$ & $21.2 \%$ & $21.5 \%$ & 0.35 \\
& $(422 / 2110)$ & $(407 / 1922)$ & $(50 / 233)$ & \\
$\%$ of depression cases $(n)$ & $19.9 \%$ & $25.7 \%$ & $33.3 \%$ & $<0.01$ \\
& $(419 / 2108)$ & $(492 / 1917)$ & $(78 / 234)$ & \\
$\%$ of anxiety cases $(n)$ & $15.7 \%$ & $19.3 \%$ & $22.6 \%$ & $<0.01$ \\
& $(331 / 2107)$ & $(373 / 1928)$ & $(53 / 234)$ & \\
$\%$ low decision latitude $(n)$ & $31.5 \%$ & $64.3 \%$ & $93.6 \%$ & $<0.01$ \\
& $(772 / 2449)$ & $(1494 / 2323)$ & $(324 / 346)$ & \\
$\%$ low home control $(n)$ & $13.5 \%$ & $10.8 \%$ & $12.4 \%$ & 0.03 \\
& $(332 / 2463)$ & $(253 / 2340)$ & $(44 / 355)$ & \\
\hline Women & & & & \\
GHQ mean $($ sd) & $3.59(5.51)$ & $4.14(6.66)$ & $3.55(6.04)$ & 0.15 \\
$\%$ of GHQ cases $(n)$ & $27.1 \%$ & $27.5 \%$ & $24.5 \%$ & 0.30 \\
& $(90 / 332)$ & $(232 / 845)$ & $(150 / 611)$ & \\
$\%$ of depression cases $(n)$ & $25.5 \%$ & $27.9 \%$ & $30.3 \%$ & 0.12 \\
& $(85 / 333)$ & $(235 / 842)$ & $(186 / 614)$ & \\
$\%$ of anxiety cases $(n)$ & $26.3 \%$ & $26.2 \%$ & $27.0 \%$ & 0.77 \\
$\%$ low decision latitude $(n)$ & $(87 / 331)$ & $(222 / 848)$ & $(166 / 615)$ & \\
$\%$ low home control $(n)$ & $8.8 \%$ & $39.8 \%$ & $76.6 \%$ & $<0.01$ \\
& $(32 / 362)$ & $(388 / 975)$ & $(657 / 858)$ & \\
& $8.5 \%$ & $7.8 \%$ & $9.2 \%$ & 0.50 \\
& $(32 / 376)$ & $(80 / 1030)$ & $(82 / 893)$ & \\
\hline
\end{tabular}

a. Differences in means tested using the F-test. Differences in proportions tested using likelihood-ratio chi-square.

scales from Phase 5. Women and men did not differ by the amount of decision latitude that they reported, but men did report significantly less control at home. When we stratified by gender and employment grade, as seen in Table 2, a significantly greater proportion of men in the lower grades were classified as depression and anxiety cases and reported low decision latitude. More men in the highest grade, however, reported low control at home. Conversely, the proportion of women classified as GHQ cases or anxiety cases did not vary significantly by employment grade. We did, however, find a gradient in the 
proportion of depression cases, with more women in the lower grades classified as depression cases, although the proportions were not significantly different. More women in the lowest grade reported low control at home, and as with the men, we found a strong gradient for decision latitude in women, with a greater proportion of those in the lowest grade reporting low control.

In Tables 3 through 6, we address our main research questions. First, did low decision latitude at work increase the risk of depression and anxiety equally for women and men? As shown in Tables 3 and 4, after adjusting for age and employment grade, both women and men with low decision latitude had significantly higher odds for depression (for women, $\mathrm{OR}=1.48, \quad \mathrm{CI}=1.15-1.89 ;$ for $\operatorname{men}, \mathrm{OR}=1.53$, $\mathrm{CI}=1.31-1.80$ ) and anxiety (for women, $\mathrm{OR}=1.29$, $\mathrm{CI}=1.03-1.62$; for men, $\mathrm{OR}=1.43, \mathrm{CI}=1.20-1.70)$. Even after adjusting for home control (Step 3), marital status, number of children, and caregiving status (Step 4), women and men with low decision latitude had increased odds for depression and, for men, an increased risk for anxiety. The effect of low decision latitude was stronger for men than it was for women, particularly in relation to anxiety disorders.

For our second research question we asked: Did low control at home increase the risk of depression and anxiety equally for women and men? Our initial analyses, where we fit home control in Step 2 and decision latitude in Step 3, did not differ from the previous analysis where we first fit decision latitude and then home control. Given the comparable findings, we refer to the same tables used to address the previous question, Tables 3 and 4 .

After adjusting for age, grade, and decision latitude (Step 3), both women and men with low control at home had significantly higher odds of suffering from depression (for women, $\mathrm{OR}=2.51$, CI $=1.77$ 3.56; for men, $\mathrm{OR}=1.86, \mathrm{CI}=1.52-2.28$ ) and anxiety (for women, $\mathrm{OR}=1.75, \mathrm{CI}=1.22-2.51$; for men, $\mathrm{OR}=1.89, \mathrm{CI}=1.52-2.35)$ than those with high control. The effect of low control at home on depression was stronger for women than men, but for anxiety, the effect was slightly stronger for men.

The independent effects of decision latitude and control at home persisted after we re-examined the analyses, controlling for marital status, number of children and caregiving status (Step 4). Low control at home more than doubled the risk for depression $(\mathrm{OR}=2.55$, $\mathrm{CI}=1.78-3.63)$ and increased the risk by almost $70 \%$ for anxiety 
Table 3

Gender-specific effects of employment grade, decision latitude and home control at Phase 3 on depression at Phase 5: OR ${ }^{a}$ and $95 \%$ CI

\begin{tabular}{|c|c|c|c|c|c|c|}
\hline & & Step 1 & Step 2 & Step 3 & Step 4 & $\begin{array}{l}\text { Step } 4 \text { repeated, excluding } \\
\text { Phase } 3 \text { depression cases }\end{array}$ \\
\hline Men & $\begin{array}{l}\text { Age 39-44 (years) } \\
45-49 \\
50-54 \\
55-64 \\
\text { Grade High } \\
\text { Middle } \\
\text { Low } \\
\text { Decision latitude }{ }^{d} \\
\text { Home control }^{d} \\
\text { Marital status }{ }^{d} \\
\text { Number of children }{ }^{d} \\
\text { Caregiving status }^{d}\end{array}$ & $\begin{array}{c}1.00 \\
0.85(0.71-1.02) \\
0.75(0.61-0.93)^{b} \\
0.59(0.48-0.74)^{b} \\
1.0 \\
1.35(1.16-1.57)^{b} \\
1.95(1.44-2.64)^{b}\end{array}$ & $\begin{array}{c}1.00 \\
0.86(0.72-1.03) \\
0.75(0.61-0.93)^{b} \\
0.59(0.48-0.74)^{b} \\
1.0 \\
1.17(1.00-1.38)^{c} \\
1.51(1.10-2.07)^{b} \\
1.53(1.31-1.80)^{b}\end{array}$ & $\begin{array}{c}1.00 \\
0.86(0.72-1.03) \\
0.77(0.62-0.95)^{b} \\
0.62(0.50-0.77)^{b} \\
1.0 \\
1.21(1.03-1.41)^{c} \\
1.52(1.11-2.09)^{b} \\
1.53(1.30-1.79)^{b} \\
1.86(1.52-2.28)^{b}\end{array}$ & $\begin{array}{c}1.00 \\
0.85(0.71-1.02) \\
0.77(0.62-0.96)^{c} \\
0.62(0.50-0.78)^{b} \\
1.0 \\
1.16(0.99-1.36) \\
1.39(1.01-1.93)^{c} \\
1.50(1.28-1.76)^{b} \\
1.92(1.57-2.36)^{b} \\
1.39(1.13-1.72)^{b} \\
1.00(0.93-1.08) \\
1.45(1.15-1.83)^{b}\end{array}$ & $\begin{array}{c}1.0 \\
0.79(0.61-1.03) \\
0.72(0.53-0.98)^{c} \\
0.71(0.52-0.96)^{c} \\
1.0 \\
1.17(0.93-1.48) \\
1.38(0.87-2.20) \\
1.15(0.92-1.44) \\
1.71(1.26-2.31)^{b} \\
1.29(0.94-1.76) \\
1.02(0.91-1.13) \\
1.59(1.16-2.18)^{b}\end{array}$ \\
\hline Women & $\begin{array}{l}\text { Age 39-44 (years) } \\
\text { 45-49 } \\
50-54 \\
55-64 \\
\text { Grade High } \\
\text { Middle } \\
\text { Low } \\
\text { Decision latitude }{ }^{d} \\
\text { Home control }^{d} \\
\text { Marital status }^{d} \\
\text { Number of children } \\
\text { Caregiving status }^{d}\end{array}$ & $\begin{array}{c}1.0 \\
0.68(0.51-0.90)^{b} \\
0.53(0.39-0.73)^{b} \\
0.46(0.33-0.62)^{b} \\
1.0 \\
1.25(0.92-1.68) \\
1.54(1.12-2.12)^{b}\end{array}$ & $\begin{array}{c}1.0 \\
0.67(0.50-0.89)^{b} \\
0.52(0.38-0.70)^{b} \\
0.45(0.33-0.61)^{b} \\
1.0 \\
1.10(0.81-1.50) \\
1.18(0.82-1.70) \\
1.48(1.15-1.89)^{b}\end{array}$ & $\begin{array}{c}1.0 \\
0.67(0.50-0.90)^{b} \\
0.52(0.38-0.71)^{b} \\
0.45(0.33-0.61)^{b} \\
1.0 \\
1.11(0.81-1.52) \\
1.20(0.83-1.73) \\
1.44(1.12-1.85)^{b} \\
2.51(1.77-3.56)^{b}\end{array}$ & $\begin{array}{c}1.0 \\
0.67(0.50-0.90)^{b} \\
0.51(0.37-0.70)^{b} \\
0.44(0.32-0.61)^{b} \\
1.0 \\
1.11(0.81-1.52) \\
1.21(0.83-1.77) \\
1.43(1.11-1.83)^{b} \\
2.55(1.78-3.63)^{b} \\
1.13(0.89-1.43) \\
1.00(0.90-1.12) \\
1.04(0.76-1.42)\end{array}$ & $\begin{array}{c}1.0 \\
0.61(0.41-0.90)^{b} \\
0.48(0.31-0.74)^{b} \\
0.40(0.26-0.63)^{b} \\
1.0 \\
1.08(0.71-1.64) \\
1.10(0.65-1.85) \\
1.15(0.81-1.64) \\
2.02(1.12-3.64)^{c} \\
1.15(0.83-1.61) \\
1.04(0.90-1.21) \\
0.72(0.44-1.18)\end{array}$ \\
\hline
\end{tabular}

a. $\mathrm{OR}=$ Odds ratio estimated by logistic regression. $\quad b . p$-value $\leq 0.01 . \quad c . p$-value $\leq 0.05$.

marital status $(0$ 
Table 4

Gender-specific effects of employment grade, decision latitude and home control at Phase 3 on anxiety at Phase 5: OR ${ }^{a}$ and $95 \%$ CI

\begin{tabular}{|c|c|c|c|c|c|c|}
\hline & & Step 1 & Step 2 & Step 3 & Step 4 & $\begin{array}{c}\text { Step } 4 \text { repeated, excluding } \\
\text { Phase } 3 \text { anxiety cases }\end{array}$ \\
\hline Men & $\begin{array}{l}\text { Age 39-44 (years) } \\
45-49 \\
50-54 \\
55-64 \\
\text { Grade High } \\
\text { Middle } \\
\text { Low } \\
\text { Decision latitude }{ }^{d} \\
\text { Home control }^{d} \\
\text { Marital status }^{d} \\
\text { Number of children }^{d} \\
\text { Caregiving status }^{d}\end{array}$ & $\begin{array}{c}1.0 \\
0.64(0.53-0.78)^{b} \\
0.50(0.39-0.63)^{b} \\
0.40(0.31-0.52)^{b} \\
1.0 \\
1.23(1.04-1.45)^{c} \\
1.55(1.10-2.18)^{c}\end{array}$ & $\begin{array}{c}1.0 \\
0.64(0.53-0.78)^{b} \\
0.50(0.39-0.63)^{b} \\
0.40(0.31-0.52)^{b} \\
1.0 \\
1.09(0.92-1.30) \\
1.26(0.88-1.79) \\
1.43(1.20-1.70)^{b}\end{array}$ & $\begin{array}{c}1.0 \\
0.64(0.53-0.78)^{b} \\
0.51(0.40-0.64)^{b} \\
0.42(0.33-0.54)^{b} \\
1.0 \\
1.12(0.94-1.34) \\
1.27(0.89-1.81) \\
1.42(1.20-1.70)^{b} \\
1.89(1.52-2.35)^{b}\end{array}$ & $\begin{array}{c}1.0 \\
0.62(0.51-0.75)^{b} \\
0.48(0.38-0.61)^{b} \\
0.40(0.31-0.51)^{b} \\
1.0 \\
1.12(0.93-1.34) \\
1.28(0.89-1.84) \\
1.43(1.19-1.70)^{b} \\
1.88(1.52-2.34)^{b} \\
1.05(0.82-1.33) \\
1.03(0.95-1.13) \\
1.72(1.34-2.21)^{b}\end{array}$ & $\begin{array}{c}1.0 \\
0.58(0.46-0.75)^{b} \\
0.49(0.36-0.66)^{b} \\
0.35(0.26-0.49)^{b} \\
1.0 \\
1.07(0.85-1.34) \\
1.15(0.73-1.82) \\
1.43(1.15-1.79)^{b} \\
1.68(1.25-2.24)^{b} \\
0.86(0.63-1.17) \\
0.97(0.87-1.07) \\
1.70(1.23-2.35)^{b}\end{array}$ \\
\hline Women & $\begin{array}{l}\text { Age 39-44 (years) } \\
45-49 \\
50-54 \\
55-64 \\
\text { Grade High } \\
\text { Middle } \\
\text { Low } \\
\text { Decision latitude }{ }^{d} \\
\text { Home control }{ }^{d} \\
\text { Marital status }^{d} \\
\text { Number of children }{ }^{d} \\
\text { Caregiving status }^{d}\end{array}$ & $\begin{array}{c}1.0 \\
0.74(0.55-0.98)^{c} \\
0.57(0.42-0.78)^{b} \\
0.40(0.29-0.56)^{b} \\
1.0 \\
1.10(0.82-1.49) \\
1.34(0.97-1.86)\end{array}$ & $\begin{array}{c}1.0 \\
0.73(0.55-0.97)^{c} \\
0.56(0.41-0.77)^{b} \\
0.40(0.29-0.56)^{b} \\
1.00 \\
1.02(0.75-1.39) \\
1.14(0.79-1.64) \\
1.28(1.00-1.65)^{c}\end{array}$ & $\begin{array}{c}1.0 \\
0.74(0.55-0.98)^{c} \\
0.57(0.41-0.78)^{b} \\
0.40(0.29-0.56)^{b} \\
1.0 \\
1.03(0.75-1.40) \\
1.15(0.80-1.65) \\
1.26(0.98-1.62) \\
1.75(1.22-2.51)^{b}\end{array}$ & $\begin{array}{c}1.0 \\
0.72(0.54-0.97)^{c} \\
0.56(0.41-0.76)^{b} \\
0.39(0.28-0.55)^{b} \\
1.00 \\
1.03(0.75-1.40) \\
1.12(0.77-1.63) \\
1.26(0.98-1.63) \\
1.69(1.18-2.43)^{b} \\
0.95(0.74-1.21) \\
1.04(0.93-1.16) \\
1.26(0.92-1.73)\end{array}$ & $\begin{array}{c}1.0 \\
0.69(0.48-1.00)^{c} \\
0.45(0.30-0.68)^{b} \\
0.37(0.24-0.57)^{b} \\
1.0 \\
0.92(0.61-1.38) \\
1.00(0.61-1.63) \\
1.20(0.86-1.67) \\
1.48(0.88-2.48) \\
0.97(0.71-1.34) \\
1.08(0.94-1.25) \\
1.01(0.65-1.56)\end{array}$ \\
\hline
\end{tabular}

a. $\mathrm{OR}=$ Odds ratio estimated by logistic regression. $\quad b$. $p$-value $\leq 0.01 . \quad$ c. $p$-value $\leq 0.05$.

$(0=$ high control) 
$(\mathrm{OR}=1.69, \mathrm{CI}=1.18-2.43)$ among women. For men, the odds for depression $(\mathrm{OR}=1.92, \mathrm{CI}=1.57-2.36)$ and anxiety $(\mathrm{OR}=1.88$, $\mathrm{CI}=1.52-2.34)$ were also significantly higher than for those with high control at home. We found that none of the social roles we examined significantly altered the relationship between home control and the outcomes for women, but we did find, for men, that being a caregiver to a disabled or ageing relative was a risk factor for depression and anxiety. Unmarried men also had higher odds of being depressed.

To test the possibility that at Phase 3 depressed or anxious women or men were more likely to report low decision latitude, we repeated our analyses using only those who were not classified as 'cases' at Phase 3 and added these findings to the last column in Tables 3 and 4. Using the equation for Step 4 (adjusting for age, grade, home control, marital and caregiving status, and number of children), the odds for depression among men with low decision latitude decreased $66 \%$, while the odds for anxiety barely changed, increasing by $2 \%$. For women with low decision latitude, the elevated risks for depression and anxiety decreased, with the odds for depression dropping 61\%, and for anxiety, $22 \%$.

While the odds also decreased when we examined the effect of low control at home using only Phase 3 non-cases, the differential effect by gender remained constant. For men, the odds for depression from having low home control decreased $18 \%$ and in women they decreased $25 \%$. The odds for anxiety in men decreased 18\%, and for women, they decreased $26 \%$. In spite of the general decrease in odds after excluding Phase 3 cases and controlling for the effects of social position and other roles, control at home remained a significant risk factor for depression in women and men and for anxiety in men.

Our third research question was: Is there an interaction between control at home and control at work that increases the risk for psychological distress? An interaction term for job decision latitude by home control was included in each of the hierarchical models. None of the terms was significant or neared significance for men or women; therefore, these data are not presented here.

Our final question was: Do these effects vary by social position, and if so, do women and men in different social positions have a greater risk of depression or anxiety from low control at home or at work? To address this question we first examined the relationship be- 
tween social position and each outcome and then considered how low control at home and work affected that relationship.

In Table 3, we found a gradient by employment grade in the risk for depression in men and women, although the odds were not always statistically significant. Women in the lowest grade had significantly higher odds of depression compared to those in the highest grade in Step 1, but after controlling for decision latitude in Step 2, the odds no longer reached a significant level. For men, the gradient was significant in Steps 1, 2, and 3, but after controlling for marital status, number of children, and caregiving status in Step 4, only the men in the lowest employment grade had significantly higher odds for depression than those in the highest grade. For both women and men, decision latitude explained a significant part of the gradient for depression. We also found a gradient by employment grade in the risk for anxiety for women and men, but after controlling for decision latitude, these differences were no longer significant.

Given the persistence of a gradient across the findings we were interested in determining if there was a gradient for control at home and work. In other words, we were interested in whether there was an increased risk for depression and anxiety for women or men in certain employment grades who had low home control and low decision latitude.

Using stratified analyses, shown in Table 5, we did not find a clear gradient for the effect of decision latitude or home control on depression in women or men. Instead we found that women and men in the middle employment grade with low decision latitude were at greatest risk for depression. Men in the middle grade also had greater odds for depression than men in other grades when there was low control at home, but it is important to note the strong and nearly significant effect low control at home had on men in the lowest grade $(\mathrm{OR}=2.03$, $\mathrm{CI}=0.92-4.47)$, a group composed of far fewer men $(n=225$ versus $n=1,900)$. For women with low control at home, we found that those in the lowest employment grade had by far the highest odds $(\mathrm{OR}=4.41, \mathrm{CI}=2.44-7.97)$ of any grade of women or men.

As shown in Table 6, we did find a gradient across employment grades for the effect of decision latitude on anxiety disorders in men. Men in the lowest grade who reported low decision latitude were at greater risk than men or women in any other grade, although the odds ratio did not reach statistical significance $(\mathrm{OR}=2.62, \mathrm{CI}=0.52-13.26)$. 
Table 5

Gender- and grade-specific effects of decision latitude and home control at Phase 3 on depression at Phase 5: OR ${ }^{a}$ and $95 \%$ CI

\begin{tabular}{|c|c|c|c|c|}
\hline & & High grade & Middle grade & Low grade \\
\hline Men & $\begin{array}{l}\text { Age 39-44 (years) } \\
\quad 45-49 \\
50-54 \\
55-64 \\
\text { Decision latitude }{ }^{d} \\
\text { Home control }{ }^{d} \\
\text { Marital status }{ }^{d} \\
\text { Number of children }{ }^{d} \\
\text { Caregiving status }{ }^{d} \\
n\end{array}$ & $\begin{array}{c}1.0 \\
0.93(0.70-1.24) \\
0.90(0.66-1.23) \\
0.74(0.53-1.03) \\
1.29(1.03-1.62)^{c} \\
1.71(1.28-2.29)^{b} \\
1.33(0.92-1.94) \\
0.98(0.88-1.11) \\
1.49(1.05-2.11)^{c} \\
2,087\end{array}$ & $\begin{array}{c}1.0 \\
0.80(0.62-1.04) \\
0.69(0.50-0.95)^{c} \\
0.52(0.37-0.73)^{b} \\
1.76(1.39-2.23)^{b} \\
2.22(1.63-3.03)^{b} \\
1.43(1.08-1.90)^{b} \\
0.99(0.89-1.11) \\
1.38(0.99-1.32) \\
1,900\end{array}$ & $\begin{array}{c}1.0 \\
0.77(0.34-1.73) \\
0.56(0.24-1.33) \\
0.65(0.31-1.35) \\
1.42(0.42-4.79) \\
2.03(0.92-4.47) \\
1.40(0.71-2.79) \\
1.19(0.89-1.58) \\
1.71(0.64-4.54) \\
225\end{array}$ \\
\hline Women & $\begin{array}{l}\text { Age 39-44 years } \\
\quad 45-49 \\
50-54 \\
55-64 \\
\text { Decision latitude }^{d} \\
\text { Home control }^{d} \\
\text { Marital status }{ }^{d} \\
\text { Number of children }{ }^{d} \\
\text { Caregiving status }{ }^{d} \\
n\end{array}$ & $\begin{array}{c}1.0 \\
0.56(0.30-1.02) \\
0.31(0.14-0.69)^{c} \\
0.41(0.17-1.03) \\
1.12(0.44-2.87) \\
1.81(0.76-4.28) \\
1.19(0.66-2.13) \\
0.98(0.74-1.30) \\
1.67(0.82-3.41) \\
320\end{array}$ & $\begin{array}{c}1.0 \\
0.73(0.49-1.10) \\
0.51(0.32-0.80)^{b} \\
0.50(0.31-0.80)^{b} \\
1.60(1.16-2.21)^{b} \\
1.82(1.05-3.14)^{c} \\
1.08(0.76-1.52) \\
0.99(0.84-1.16) \\
1.10(0.70-1.74) \\
792\end{array}$ & $\begin{array}{c}1.0 \\
0.64(0.36-1.15) \\
0.63(0.35-1.13) \\
0.40(0.23-0.70)^{b} \\
1.27(0.81-1.97) \\
4.41(2.44-7.97)^{b} \\
1.15(0.77-1.74) \\
1.00(0.84-1.19) \\
0.78(0.44-1.38) \\
588\end{array}$ \\
\hline
\end{tabular}

a. OR $=$ Odds ratio estimated by logistic regression. $\quad b . p$-value $\leq 0.01 . \quad c . p$-value $\leq 0.05$.

d. marital status $(0=$ married, $1=$ unmarried $)$, number of children $(0=$ none), caregiving status $(0=$ not a caregiver $)$, decision latitude $(0=$ high control $)$, home control $(0=$ high control $)$. 
Table 6

Gender- and grade-specific effects of decision latitude and home control at Phase 3 on anxiety at Phase 5: OR ${ }^{a}$ and $95 \%$ CI

\begin{tabular}{|c|c|c|c|c|}
\hline & & High grade & Middle grade & Low grade \\
\hline Men & $\begin{array}{l}\text { Age 39-44 years } \\
\quad 45-49 \\
50-54 \\
55-64 \\
\text { Decision latitude }^{d} \\
\text { Home control }^{d} \\
\text { Marital status }^{d} \\
\text { Number of children }^{d} \\
\text { Caregiving status } \\
n \\
n\end{array}$ & $\begin{array}{c}1.0 \\
0.61(0.45-0.82)^{b} \\
0.52(0.37-0.73)^{b} \\
0.38(0.26-0.56)^{b} \\
1.26(0.98-1.63) \\
2.17(1.60-2.94)^{b} \\
1.29(0.85-1.96) \\
1.01(0.89-1.15) \\
1.26(0.83-1.90) \\
2,086\end{array}$ & $\begin{array}{c}1.0 \\
0.62(0.47-0.82)^{b} \\
0.48(0.34-0.69)^{b} \\
0.35(0.23-0.51)^{b} \\
1.58(1.22-2.04)^{b} \\
1.86(1.33-2.58)^{b} \\
0.96(0.70-1.33) \\
1.03(0.91-1.16) \\
2.00(1.41-2.82)^{b} \\
1,911\end{array}$ & $\begin{array}{c}1.0 \\
0.55(0.21-1.41) \\
0.24(0.07-0.79)^{c} \\
0.76(0.35-1.68) \\
2.62(0.52-13.26) \\
0.78(0.27-2.25) \\
1.12(0.50-2.50) \\
1.25(0.90-1.73) \\
3.59(1.34-9.67)^{b} \\
225\end{array}$ \\
\hline Women & $\begin{array}{l}\text { Age 39-44 years } \\
\quad 45-49 \\
50-54 \\
55-64 \\
\text { Decision latitude }^{d} \\
\text { Home control }^{d} \\
\text { Marital status }^{d} \\
\text { Number of children }^{d} \\
\text { Caregiving status } \\
n \\
n\end{array}$ & $\begin{array}{c}1.0 \\
0.73(0.40-1.33) \\
0.51(0.24-1.08) \\
0.33(0.12-0.90)^{c} \\
1.21(0.49-2.99) \\
0.93(0.37-2.36) \\
1.01(0.56-1.81) \\
1.03(0.78-1.36) \\
2.13(1.07-4.26)^{c} \\
319\end{array}$ & $\begin{array}{c}1.0 \\
0.80(0.53-1.19) \\
0.51(0.32-0.82)^{b} \\
0.41(0.25-0.68)^{b} \\
1.54(1.11-2.13)^{b} \\
1.50(0.86-2.60) \\
0.96(0.68-1.37) \\
0.95(0.80-1.12) \\
1.20(0.75-1.91) \\
797\end{array}$ & $\begin{array}{c}1.0 \\
0.63(0.35-1.14) \\
0.63(0.35-1.13) \\
0.39(0.22-0.68)^{b} \\
0.91(0.59-1.40) \\
2.55(1.42-4.59)^{b} \\
0.88(0.58-1.35) \\
1.14(0.95-1.36) \\
1.04(0.59-1.86) \\
588\end{array}$ \\
\hline
\end{tabular}

a. $\mathrm{OR}=$ Odds ratio estimated by logistic regression. $\quad$ b. $p$-value $\leq 0.01$.

c. $p$-value $\leq 0.05$.

d. marital status $(0=$ married, $1=$ unmarried $)$, number of children $(0=$ none $)$, caregiving status $(0=$ not a caregiver $)$, decision latitude $(0=$ high control $)$, home control $(0=$ high control $)$. 
As we noted previously, the lack of statistical significance may be a function of the relatively smaller sample size for men in the lowest grade. We did not find a clear gradient for women with low decision latitude across employment grades. Instead, we found that women in the middle grade had a significant risk for anxiety disorders $(\mathrm{OR}=1.54, \mathrm{CI}=1.11-2.13)$ and a greater risk than women in the other grades.

After controlling for age and decision latitude, we also found a gradient for control at home on anxiety. We found women in the lowest grade and men in the middle and highest grades to have the highest odds for anxiety disorders if they reported low control at home (for women, $\quad \mathrm{OR}=2.55, \quad \mathrm{CI}=1.42-4.59 ; \quad$ for men, middle grade, $\mathrm{OR}=1.86, \mathrm{CI}=1.33-2.58$; and, highest grade, $\mathrm{OR}=2.17, \mathrm{CI}=1.60$ 2.94). In addition to low control at home, we found that for men in the middle and low grades and women in the high grade, the greatest risk factor for anxiety disorders was if they also provided care to disabled or ageing relatives.

\section{Discussion}

In this study we investigated the relationships among gender, decision latitude, home control and the risk for depression and anxiety across three employment grades. We hypothesised that low job and home control would increase the risk for depression and anxiety. We expected home control to contribute more to the risk for women's psychological ill health and decision latitude for men's. We also believed that across employment grades we would find a gradient in risk for each outcome and that low levels of job and home control would explain part of the gradient.

As expected, a greater proportion of women than men were classified as depression and anxiety cases and this was true across nearly all employment grades. Both younger women and men were more likely to be depressed than those who were older, but unlike previous studies, number of children was not a significant predictor for depression or anxiety. This, in part, may be due to the fact that a large proportion of women in the middle and high employment grades and men in the lowest grade were childless (as shown in Table 1). It may also be, that given the age of the participants (from 39 to 64), few had young chil- 
dren or children living at home. In fact, for this age group, the additional strain from family or social obligations may lie more with providing care to elderly or ageing spouses and parents than with raising children. We found this to be particularly true for men. Men who were caregivers consistently had a significantly higher risk for depression and anxiety.

We found that low decision latitude at Phase 3 predicted a risk for depression at Phase 5 among women and men and this risk did not diminish after controlling for home control, marital status, number of children, and caregiving status. Although the effect of low decision latitude on depression and anxiety was stronger for men than women, as we expected, the effect for women, particularly for depression, was remarkable. Women with low decision latitude had more than a $40 \%$ greater risk for depression than women with high control, while men's odds were $50 \%$ greater if they reported low decision latitude. When we stratified by gender and social position as shown in Tables 5 and 6 , we found that the risk was not evenly distributed across social position for women or men. Both women and men in the middle employment grade with low decision latitude were at significantly greater risk for depression than those in the lowest and highest grades. The same pattern existed for anxiety, except that men in the low grade also had an elevated risk that was not statistically significant.

Both women and men with low control at home were at significantly greater risk for depression and anxiety. One striking finding was that women with low control at home had over twice the risk for depression than women with high control even after controlling for marital status, number of children, and caregiving status. Also impressive was the substantial effect low home control had on men's risk for depression.

In our confirmation analyses, where we examined only those who were not cases at Phase 3, the effect of decision latitude and control at home on depression and anxiety either decreased or was virtually unchanged for women and men. The largest decrease in odds was when we examined the effect of decision latitude on depression. These changes may have been due to the fact that the relationship between depression caseness at Phase 3 and Phase 5 was so great and not independent of decision latitude that the group that remained after cases were excluded had an unusual distribution of decision latitude. The relatively even percentage of change in odds ratios (decreasing 18-26\%) 
suggests that this is not the case for the relationship among control at home and depression and anxiety, nor is it situation between decision latitude and anxiety, where the odds ratios increased for men $(2 \%)$ and decreased for women $(22 \%)$.

We had hypothesised that low decision latitude and low control at home would be a psychologically harmful combination, but did not find any evidence for this. Instead we found that exposures to low control in both the home and work environment were unique to each environment, each with a main effect that increased the risk for depression, and for men increased the risk for anxiety. In subsequent analyses we also tested for interactions between decision latitude and all of the social roles we studied (marital status, number of children, and caregiving status), and again, did not find any evidence of an additional risk for depression or anxiety in women or men. What we did not test here, however, were the specific effects of spillover or workfamily conflict. An investigation examining more precise questions on balancing the demands and responsibilities of work and family and the effect of this on psychological and physical health is currently underway. Similarly, it is beyond the scope of this paper to test for any beneficial or buffering effects from social support or rewards from work and home that may explain the lack of an interaction between home and work.

For this investigation we were also interested in whether a social class gradient existed for women and men with depression and anxiety. When we compared the low and middle grades to the highest in Tables 3 and 4, we did find a linear pattern: women and men in the lowest grades had the highest risk for depression and anxiety. That this gradient is reduced (and at times is no longer statistically significant) but still persists after controlling for decision latitude, home control, number of children, and marital and caregiver status, suggests that other factors are also at play. Previous analyses in this cohort suggest that social support, life events, and material problems are also important in explaining the gradient (Stansfeld et al., 1998).

One underlying assumption in the job stress and gender frameworks, or perhaps in researchers' use of them, is that, with little regard for social position, men's identity is tied more to their role at work and women's to their roles at home. This assumption leads to the common approach of narrowly looking only at the effect of stressful job characteristics for men and the characteristics of home or social roles for 
women. Our findings show, however, that low control at home, just like low control on the job, affect the psychological morbidity of both women and men differently, and this is, in part, because of their social position. As shown in Tables 5 and 6, women in the lowest employment grade with low control at home had a significantly higher risk for depression than men across all grades and women in higher grades. Women and men in the middle and highest grade had somewhat comparable risks. The findings for anxiety are quite different, for they show an inverse gradient in risk for women and men. Men in the highest grade with low control at home were at higher risk for anxiety than men in lower grades while women in the lowest grade had a higher risk than women in higher grades. We conclude, as others have done before us (Arber, 1991; Hall, 1989), the identification to or measurement of only one role is too simplistic and does not take into account the different experiences women and men face at work and in the home. In the future, models need to be modified to incorporate work, home, and social position variables for men and women.

The importance of low home control as a risk factor for depression and anxiety brings into question the meaning of the construct. In the sociology of work and family, the construct has been described and interpreted in two different ways. The first is that control at home is the ability to maintain family and home obligations and cope with dayto-day stressors. In this sense, the link between low control at home and psychological distress may indicate a lack of resources for coping with excessive demands from housework and family responsibilities (Lennon and Rosenfield, 1992; Pearlin and Schooler, 1978; Pearlin, 1989) or material resources (Walters et al., 1996) that make services and support more easily accessible. This interpretation leaves some confusion about whether the construct is a description of control, demands, or something more latent that includes both demands and control.

The second common interpretation relates to inequities in the division of labour at home and the roots of the inequities (Bird, 1999). In other words, control at home is based on power and power within relationships. High control at home, for example, may be having the power to assign household tasks to family members and assure they are done in an appropriate way, or, perhaps, control over the household income to be used at one's discretion. Rosenfield (1989) found that low power (operationalised as the proportion of personal income to total household income) accounted for gender differences in psycho- 
logical distress, but that the relationship was mediated by one's level of personal control. Using this perspective, men and women may interpret the construct differently based on their relationships with family members or their adherence to traditional gender roles. Those who share household and familial responsibilities may value the work differently than those who perform more conventional roles. The relationship between power and control emphasizes the importance of gender relations and reinforces the need to include additional, more precise questions regarding the division of labour and inequities at home. Moreover, for future studies there is a need to decipher how power and control are interpreted differently among men, women, and people from different social positions.

In sum, we found support for an integrated model to examine factors associated with depression and anxiety in women and men. For women we found that a lack of control at home and work predicted later development of depression, and for men, low control at home and work increased odds of depression and anxiety. We discovered that, in addition to age and gender, risk factors for depression and anxiety included the level of control participants reported at home and work and where in social hierarchy women and men sit. In other words, risks for depression and anxiety, such as low control at home and work, are not evenly distributed across different social positions, although the patterns are much more consistent for women. Women in the lowest or middle employment grades who reported low decision latitude or low control at home were at most risk for depression and anxiety. Men in the middle grade with low decision latitude were at risk for depression, but those in the lowest grade were at risk for anxiety. Men in the middle and highest grades, however, were at greatest risk for both outcomes if they reported low control at home. While we suggest that control at home and at work are included in models examining health inequalities, we also emphasise the need for more theoretical work on the meaning of the construct of control at home and how it varies by gender and social position. 


\section{Acknowledgements}

The Whitehall II study has been supported by grants from the Economic and Social Research Council (L128251052); Medical Research Council; British Heart Foundation; Health and Safety Executive; Department of Health; National Heart Lung and Blood Institute (RO1-HL36310), US, NIH; National Institute on Aging (RO1-AG13196), US, NIH; Agency for Health Care Policy Research (RO1-HS06516); and, the John D. and Catherine T. MacArthur Foundation Research Networks on Successful Midlife Development and Socio-economic Status and Health. This work was carried out while Joan M. Griffin was a NATO/NSF post-doctoral fellow with the Department of Epidemiology and Public Health at University College London. Michael Marmot was supported by an MRC Research Professorship. We are grateful to Professor Sara Arber and the anonymous reviewers for their helpful comments and suggestions on an earlier draft of this paper. We wish to thank all participating civil service departments and their welfare, personnel, and establishment officers; the Occupational Health and Safety Agency; the Council of Civil Service Unions; all participating civil servants in the Whitehall II study; and all members of the Whitehall II study team.

\section{References}

Alfredsson, L., and Theorell, T. (1983), "Job characteristics of occupations and myocardial infarction risk: Effect of possible confounding factors", Social Science and Medicine, vol. 17, p. 1497-1503.

ANESHENSEL, C.S. (1992), "Social stress: Theory and research", Annual Review of Sociology, vol. 18, p. 15-38.

ARBER, S. (1991), "Class, paid employment and family roles: Making sense of structural disadvantage, gender and health status", Social Science and Medicine, vol. 32, p. $425-436$.

ARBER, S. (1997), “Comparing inequalities in women's and men's health: Britain in the 1990s", Social Science and Medicine, vol. 44, p. 773-787.

Arber, S., GilberT, G.N., and DALE, A. (1985), "Paid employment and women's health: A benefit or a source of role strain?", Sociology of Health and Illness, vol. 7, p. 375-400.

Bartley, M., Popay, J., and Plewis, I. (1992), "Domestic conditions, paid employment and women's experience of ill-health", Sociology of Health and Illness, vol. 14, p. 313-343.

Bebbington, P., Hurry, J., Tennant, C., Stuart, E., and Wolgast, E. (1981), "Epidemiology of mental disorders in Camberwell", Psychological Medicine, vol. 11, p. 561-579. 
BIRD C.E. (1999), "Gender, household labor, and psychological distress: The impact of the amount and division of housework", Journal of Health and Social Behavior, vol. 40, p. 32-45.

BIRD C.E., and Ross C.E. (1993), "Houseworkers and paid workers: Qualities of the work and effects on personal control", Journal of Marriage and the Family, vol. 55, p. $913-925$.

Bosma, H., Marmot, M.G., Hemingway, H., Nicholson, A.C., Brunner, E., and STANSFELD, S.A. (1997), "Low job control and risk of coronary heart disease in Whitehall II (prospective cohort) study", British Medical Journal, no. 314, p. 558565.

DoHrenwend, B.P. (1990), "Socioeconomic status (SES) and psychiatric disorders", Social Psychiatry and Psychiatric Epidemiology, vol. 25, p. 41-47.

FERREE, M.M. (1990), "Beyond separate spheres: Feminism and family research", Journal of Marriage and the Family, vol. 52, p. 866-884.

FrONE, M.R. (1997), "Relation of work-family conflict to health outcomes: A fouryear longitudinal study of employed parents", Journal of Occupational and Organizational Psychology, vol. 70, p. 325-335.

Frone, M.R., Russell, M., and Barnes, G.M. (1996), "Work-family conflict, gender, and health-related outcomes: A study of employed parents in two community samples", Journal of Occupational Health Psychology, vol. 1, p. 57-69.

Goldberg, D.P. (1972), Detecting Psychiatric Illness by Questionnaire, London, Oxford University Press, Maudsley Monograph no. 21.

GoldBerg, D.P., and Hillier, V. (1978), "A scaled version of the General Health Questionnaire", Psychological Medicine, vol. 9, p. 139-145.

Gove, W., and Tudor, J. (1973), "Adult sex roles and mental illness", American Journal of Sociology, vol. 78, p. 812-835.

GRZYWACZ, J.G., and MARKS, N.F. (2000), "Reconceptualizing the work-family interface: An ecological perspective on the correlates of positive and negative spillover between work and family", Journal of Occupational Health Psychology, vol. 5, p. 111-126.

HAAVIO, M.E. (1986), "Inequalities in health and gender", Social Science and Medicine, vol. 22, p. 141-149.

HALL, E.M. (1989), "Gender, work control, and stress: A theoretical discussion and an empirical test", International Journal of Health Services, vol. 19, p. 725-745.

HALL, E.M. (1992), "Double exposure: the combined impact of the home and work environments on psychosomatic strain in Swedish women and men", International Journal of Health Services, vol. 22, p. 239-260.

Hall, E.M., and JOHnson, J.V. (1988), "Depression in unemployed Swedish women", Social Science and Medicine, vol. 27, p. 1349-1355.

Hall, E.M., JOHNSON, J.V., and Tsou, T.S. (1993), "Women, occupation, and risk of cardiovascular morbidity and mortality", Occupational Medicine, vol. 8, p. 709719.

Hare, E.H., and SHAw, G.K. (1965), Mental Health on a New Housing Estate: A Comparative Study of Health in Two Districts in Croydon, London, Oxford University Press.

Hochschild, A.R. (1989), The Second Shift: Working Parents and the Revolution at Home, New York, Viking. 
Hodiamont, P., Peer, N., and Syben, N. (1987), "Epidemiological aspects of psychiatric disorder in a Dutch Health Area", Psychological Medicine, vol. 17, p. 495505.

Hunt, S., McEwen, J., and McKennA, S.P. (1985), "Social inequalities and perceived health", Effective Health Care, vol. 2, p. 151-160.

JoHnson, J.V., and HALl, E.M. (1988), "Job strain, work place social support, and cardiovascular disease: A cross-sectional study of a random sample of the Swedish working population", American Journal of Public Health, vol. 78, p. 1336-1342.

JOHnson, J.V., and HALl, E.M. (1995), "Class, work and health", in: B.C. Amick, S. Levine, A.R. Tarlov, and D. Chapman Walsh, eds., Society and Health, Oxford, Oxford University Press.

Johnson, J.V., Hall, E.M., and Theorell, T. (1989), "Combined effects of job strain and social isolation on cardiovascular disease morbidity and mortality in a random sample of the Swedish male working population" Scandinavian Journal of Work, Environment and Health, vol. 15, p. 271-279.

KARASEK, R. (1979), "Job demands, job decision latitude, and mental strain: Implications for job redesign", Administrative Science Quarterly, vol. 24, p. 285-307.

Karasek, R., and Theorell, T. (1990), Healtby Work: Stress Productivity and the Reconstruction of Working Life, New York, Basic Books.

Karasek, R., Gordon, G., Pietrokovsky, C., Frese, M., and Pieper, C. (1985), Job Content Instrument: Questionnaire and User's Guide, Los Angeles, CA, University of Southern California.

KESSLER, R.A. (1994), "Lifetime and 12-month prevalence of DSM III R psychiatric disorders in the United States", Archives of General Psychiatry, vol. 51, p. 8-19.

Kessler, R.A., and MCRAE, J.A. (1981), "Trends in the relationship between sex and psychological distress: 1957-1976”, American Sociological Review, vol. 46, p. 443-452.

KESSLER-HARris, A. (1976), "Women, work, and the social order", in: B. Carroll, ed., Liberating Women's History: Theoretical and Critical Essays, Urbana, University of Illinois Press.

LENNON, M.C., and Rosenfield, S. (1992), "Women and mental health: The interaction of job and family conditions", Journal of Health and Social Behavior, vol. 33, p. 316-327.

Lin, T., CHU, H., RiN, H., Hsu, C., YEH, E., and CHEN, C. (1989), "Effects of social change on mental disorder in Taiwan: Observation based on a 15-year follow up study of a general population in three communities", Acta Psychiatr Scand Suppl, vol. 348, p. 11-34.

LOMBARDI, E.L., and UlBRICH, P.M. (1997), "Work conditions, mastery and psychological distress: Are housework and paid work contexts conceptually similar?”, Women and Health, vol. 26, p. 17-39.

Lundberg, U., Mardberg, B., and Frankenhaeuser, M. (1994), "The total workload of male and female white collar workers as related to age, occupational level, and number of children", Scandinavian Journal of Psychology, vol. 35, p. 315327.

Marmot, M.G., Davey Smith, G., and Stansfeld, S.A. (1991), "Health inequalities among British civil servants: The Whitehall II study", Lancet, vol.337, p. $1387-1393$. 
McDonough, P., Williams, D.R., House, J.S., and Duncan, G.J. (1999), “Gender and the socioeconomic gradient in mortality", Journal of Health and Social Behavior, vol. 40, p. 17-31.

MCLANAHAN, S.S., and GLASS, J. (1985), "A note on the trend in sex differences in psychological distress", Journal of Health and Social Behavior, vol. 26, p. 328-336.

Mirowsky, J., and Ross, C. (1989), Social Causes of Psychological Distress, New York, Aldine.

MoEN, P. (1989), "Social integration and longevity: An event history analysis of women's roles and resilience", American Sociological Review, vol. 54, p. 635-647.

NATHANSON, C.A. (1980), "Social roles and health status among women: The significance of employment", Social Science and Medicine, vol. 14A, p. 463-471.

OAKLEY, A. (1974), The Sociology of Housework, New York, Pantheon.

PASSANNANTE, M.R., and NATHANSON, C.A. (1985), "Female labor force participation and female mortality in Wisconsin 1974-1978", Social Science and Medicine, vol. 21, p. 655-665.

PEARLIN, L.I. (1989), "The sociological study of stress", Journal of Health and Social Behavior, vol. 30, p. 241-256.

PEARLIN, L.I., and SCHOOLER, C. (1978), "The structure of coping”, Journal of Health and Social Behavior, vol. 19, p. 2-21.

Rosenfield, S. (1989), "The effects of women's employment: Personal control and sex differences in mental health", Journal of Health and Social Behavior, vol. 30, p. 77-91.

SChNAld, P.L., LANDisbergis, P.A., and BAKER, D. (1994), "Job strain and cardiovascular disease", Annual Review of Public Health, vol. 15, p. 381-411.

SchoOler, C., KoHn, M.L., Miller, K.A., and Miller, J. (1983), "Housework as work", in: C.A. Schooler and M.L. Kohn, eds., Work and Personality: An Inquiry Into the Impact of Social Stratification, Norwood, NJ, Ablex Publishing Co.

STANSFElD, S.A., and MARMOT, M.G. (1992), "Social class and minor psychiatric disorder in British civil servants: A validated screening survey using the General Health Questionnaire", Psychological Medicine, vol. 22, p. 739-749.

Stansfeld, S.A., NORTH, F.M., White, I., and Marmot, M.G. (1995), "Work characteristics and psychiatric disorder in civil servants in London", Journal of Epidemiology and Community Health, vol. 49, p. 48-53.

STANSFEld, S.A., HeAD, J.M., and MARMOT, M.G. (1998), "Explaining social class differences in depression and well being", Social Psychiatry and Psychiatric Epidemiology, vol. 33, p. 1-9.

Stansfeld, S.A., Fuhrer, R., Shipley, M.J., and Marmot, M.G. (1999), "Work characteristics predict psychiatric disorder: Prospective results from the Whitehall II Study", Journal of Occupational and Environmental Medicine, vol. 56, p. 302-307.

Theorell, T., Harms-Ringdahl, K., Ahlberg-Hulten, G.K., and Westin, B. (1991), "Psychosocial job factors and symptoms from the locomotor system - A multicausal analysis", Scandinavian Journal of Rehabilitation Medicine, vol. 23, p. 165173.

Townsend, P., and Davidson, N. (1982), Inequalities in Health, Harmondsworth, Penguin. 
Verbrugge, L. (1983), "Multiple roles and physical health of women and men", Journal of Health and Social Behavior, vol. 24, p. 16-30.

Walters, V., Lenton, R., French, S., Eyles, J., Mayr, J., and Newbold, B. (1996), "Paid work, unpaid work and social support: A study of the health of male and female nurses", Social Science and Medicine, vol. 43, p. 1627-1636.

WARR, P. (1990), "The measurement of well being and other aspects of mental health", Journal of Occupational Psychology, vol. 63, p. 193-210.

WortMAn, C., Biernat, M., and LANG, E. (1991), "Coping with role overload", in: M. Frankenhaeuser, U. Lundberg, and M. Chesney, eds., Women, Work, and Health: Stress and Opportunities, New York, Plenum Press, p. 85-110. 